\title{
LA TRADICIÓN HISTÓRICA DE LA TELERREALIDAD: CALLEJEROS Y VIDAS ANÓNIMAS
}

\author{
Brenda Vázquez-La Hoz: Productora Faro. España \\ brendavicus@hotmail.com \\ Mercedes Román-Portas: Universidad de Vigo. España \\ mroman@uvigo.es
}

\section{RESUMEN}

La tradición histórica de la telerrealidad: Callejeros y Vidas Anónimas es un artículo de investigación que ofrece un recorrido por los orígenes de la también llamada televisión callejera, a través de la historia del cine y de la televisión. Este texto pretende sentar las bases históricas de un género tan en auge en la actualidad, y que se caracteriza por estar tan próximo de la información y de la ficción. Por otro lado, tiene como objetivo descubrir algunas de sus claves del éxito, en concreto, a través del estilo de grabación de los programas Callejeros (Cuatro) y Vidas Anónimas (La Sexta). Estos formatos comparten con los orígenes del cine la pasión por la vida, pero añaden una mayor dramatización de los hechos para atrapar a la audiencia de principio a fin. La cámara se convierte en un personaje dramático, que quiere conocer historias y hurgar en los sentimientos de sus protagonistas. Su estilo de grabación imita a la vida misma, a través del Plano Secuencia, y consigue una gran identificación en los telespectadores, gracias al trato cercano de los reporteros. Callejeros ha creado escuela y Vidas Anónimas ha dado un paso más en la telerrealidad.

PALABRAS CLAVE: Cine - Telerrealidad - Dramatización - Cotidianidad Identificación.

\footnotetext{
${ }^{1}$ Autor correspondiente

Brenda Vázquez-La Hoz: Reportera de televisión. Productora Faro. Vigo, Pontevedra, España Correo: brendavicus@hotmail.com
} 


\title{
THE HISTORIC TRADITION OF REALITY TV: CALLEJEROS AND ANONYMOUS LIVES
}

\begin{abstract}
The historical tradition of reality TV: Callejeros and Vidas Anónimas is an article of investigation that offers a travel trough the origins of the, also known as street TV, through the history of cinema and TV. This text pretends to lay the groundwork of a gender wich is on the rise nowadays, and is charactericed for being close to the real information and the fiction. In other way, it has as and objective to discover the key of its success, specifically trough the recording style of the TV shows Callejeros (Cuatro) and Vidas Anónimas (La Sexta). Those formats share the passion for life that the movies have, but those TV shows formats add more dramatization of the facts to catch the audience from the beginning till the end. The camera turns into a dramma character, who wants to know all about those stories and poke into our characters feelings. It recording style imitates life itselve, though a sequence shot, and it reach a great identification into the audience, due to the close treatment of the reporters. Callejeros has created a school and Vidas Anónimas took a new step into reality TV.
\end{abstract}

KEY WORDS: Cinema -Reality TV- Dramatization -Daily- Identification.

\section{INTRODUCCIÓN}

La tradición histórica de la telerrealidad: Callejeros y Vidas Anónimas es un trabajo de investigación que parte de la hipótesis de que los programas de reportajes, que llenan cada día las parrillas de nuestras televisiones, consisten en dirigir a personas corrientes en su día a día para que actúen y formen parte del espectáculo audiovisual. Los reporteros de estos formatos se convierten en directores de la cotidianidad de ciudadanos anónimos, que se transforman a su vez en actores de su propia vida. La realidad es el escenario en el que reportero, operador de cámara y personaje principal, junto a personajes secundarios, actúan para mostrar al telespectador fragmentos de vidas anónimas.

Hemos escogido los citados programas, ya que se trata, según nuestro parecer, de los mejores ejemplos de formatos de reportajes basados en el equilibrio entre la espontaneidad de personas corrientes y la dirección del equipo de grabación. Consideramos que el programa de Cuatro ha creado escuela y que el de La Sexta ha sabido diferenciarse de los demás formatos similares, a través de una mayor dramatización de los hechos, con un guión previo, para mostrar así otra cara de la realidad cotidiana. 
El director del Centro Dramático Nacional, Gerardo Vera, se dirigió a sus actores en un ensayo de su versión de El Rey Lear, de William Shakespeare, poniendo como ejemplo a Callejeros para conseguir de ellos una actuación llena de verdad. Les dijo:

¿No veis Callejeros, el programa de Cuatro? Ahí se escucha cómo habla un drogadicto o una prostituta. Se puede saber cómo dicen que tienen frío, que les duele algo o que han perdido a un hijo. Se parece a la parte más tremenda del alma. Si abres esas puertas, las puertas del alma humana... ¡Qué lejos estamos de ella!". Vera recordó también las palabras del crítico teatral y literario polaco Jan Kott: “El espectador contemporáneo se acerca a menudo a la contemporaneidad de Shakespeare cuando encuentra en sus tragedias el reflejo de su propia realidad. ${ }^{2}$

\section{METODOLOGÍA}

Pero en este artículo queremos centrarnos en explicar la tradición histórica que precede a este tipo de formatos, la base sobre la cual, a lo largo de la evolución del cine y de la televisión, se han ido construyendo los cimientos de la telerrealidad, que tanto éxito tiene en la actualidad y que se caracteriza por la mezcla de géneros, sobre todo por estar tan próxima de la información y de la ficción. Así, Mariano Cebrián Herreros la define del siguiente modo: "No es ningún género exclusivamente de ficción, ni de realidad, ni de concurso, sino una combinación de todos ellos con múltiples variantes. A todo ello se denomina telerrealidad" (Cebrián Herreros, 2004, p. 171).

El presente estudio se basa en el método lógico-histórico, a través de este método se establece la necesaria correspondencia entre los elementos de los métodos lógico e histórico, proyectando el análisis de la evolución histórica de los fenómenos, con la proyección lógica de su comportamiento futuro.

\section{ANÁLISIS Y DISCUSIÓN}

\subsection{Orígenes de la información audiovisual y del reportaje}

El cine y la telerrealidad en televisión abren una ventana al mundo, ya que muestran e imitan situaciones de la vida cotidiana. Los ciudadanos anónimos que conforman la sociedad son los personajes principales, tanto del espectáculo social (cine), como del individual (televisión). La telerrealidad no es algo nuevo sino que el interés por la cotidianidad del ser humano se remonta al nacimiento del cine y de la pequeña pantalla.

\footnotetext{
${ }^{2}$ Declaraciones extraídas de la entrevista realizada al director del Centro Dramático Nacional, Gerardo Vera, en El País Semanal, en su número 1.637, publicada el 10 de febrero de 2008, p. 18.
} 
Así, el sociólogo Pierre Sorlin afirma que "los actores del cine son gente de carne y hueso: cuando se les describe en entornos reales y participan en historias relacionadas con problemas diarios" (Sorlin, 1996, pp. 14-15). Por su parte, el historiador Ángel Luis Hueso asegura que

la sociedad se encuentra vinculada profundamente a la realidad audiovisual y el cine se ha ido convirtiendo no sólo en un espectáculo de amplia difusión geográfica y social, sino en un escaparate en el que se muestran muchas de las peculiaridades de nuestro mundo (Hueso Montón, 1998, p. 19).

\subsection{El nacimiento del cine y del cine reportaje}

Los primeros acontecimientos que registró la cámara cinematográfica fueron los de la vida cotidiana. Los hermanos Lumière, comerciantes de la óptica y de la química, patentaron el nombre de cinematógrafo y el 28 de diciembre de 1895 hicieron una demostración en Francia de su invento. A los espectadores les costaba entender que lo que pretendían era acercarse lo más posible a la realidad (Ituarte y Letamendi, 2002, p. 37-38).

El mayor éxito de los inventores de Lyon lo logró La llegada de un tren a la estación de La Ciotat (L`Arrivée dún train à La Ciotat), proyección que provocó pánico en la sala. "Se cuenta que los espectadores asustados por la expectativa de que la locomotora se precipitaba sobre ellos, se levantaban de sus asientos profiriendo gritos de desesperación" (Ituarte \& Letamendi, 2002, pp. 47-48). Los hermanos Lumière estaban muy interesados en el movimiento e hicieron identificar a la audiencia su visión con la del ojo de la cámara, convertida por primera vez en personaje dramático, consiguiendo así su implicación en las historias ${ }^{3}$ (Sadoul, 1998, p.17-19).

El cine nace como documento de la sociedad parisina y de todo lo que la rodea. La salida de los obreros de la fábrica (La sortie des ouvriers d'usine) es la película más significativa de los Lumière, ya que por primera vez aparece como protagonista el público potencial del espectáculo: el proletariado (Gubern, 1997, pp. 21-26).

A la Rusia de los zares llegó el cinematógrafo Lumière en mayo de 1896 para rodar la coronación de Nicolás II, pero su consolidación como espectáculo fue lenta. A principios del siglo XX, la actualidad se incorporó al cine, siendo desde sus orígenes, un inventario documental y un testimonio de la memoria histórica del hombre. Pero como advierte Jesús García Jiménez, "el riesgo informativo de la cámara cinematográfica era el registro plano y mecanicista, sin profundizar en la investigación de las causas que provocan los acontecimientos" (García Jiménez, 1999, p. 1, Tomo I).

\footnotetext{
${ }^{3}$ En los programas de reportajes de telerrealidad, como Callejeros (Cuatro) y Vidas Anónimas (La Sexta), la cámara se convierte en los ojos de la audiencia, a través del Plano Subjetivo y del Plano Secuencia, aumentando así la identificación e implicación de ésta con la historia que se le muestra
} 
Se trataba de escaparates de realidad sin análisis ni investigación, objetivos imprescindibles que compartirán en un futuro los reportajes.

A Lenin no se le escapó la enorme trascendencia social del cinematógrafo, y en 1922 afirmó "de todas las artes, el cine es para nosotros la más importante" (Cit. en Gubern, 1997, pp. 145-146). Sergei M. Eisenstein se convirtió en el primer realizador soviético con el éxito de El acorazado Potemkin (Bronenosets Potyomkin, 1925), que nació del ambicioso proyecto de realizar una película sobre los acontecimientos revolucionarios de 1905: la sublevación de la marinería del acorazado Príncipe Potemkin. Eisenstein creó con su característico montaje rítmico, preciso y casi matemático un drama épico, en el que la masa era el verdadero protagonista ${ }^{4}$, convirtiéndose en una obra maestra decisiva en la evolución histórica del cine (Sadoul, 1998, p. 167-168).

A continuación, vamos a realizar un recorrido por los diferentes movimientos cinematográficos que apostaron por la realidad para contar una historia. Todas estas corrientes son los orígenes de los actuales formatos de telerrealidad que se emiten cada día con éxito en la televisión española.

\subsection{El Cine-Ojo de Dziga Vertov}

El soviético Dziga Vertov fue el primer autor que percibió la posibilidad de los noticiarios cinematográficos como género informativo. En 1922 reunió al grupo documentalista Kinoki para experimentar su teoría sobre el cine. De este modo, surgió el movimiento Kino-Glaz o Cine-Ojo, que rechazaba el guión o argumento previo y el drama cinematográfico. Confiaba en la capacidad de la cámara para mostrar los acontecimientos de la vida diaria tal como acontecen. Estaba interesado en agitar la mente del espectador y en hacerle pensar, utilizando un montaje muy ágil. Vertov decía "yo soy el Cine-Ojo; soy la máquina que muestra el mundo tal como es" (García Jiménez, 1999, p. 2, Tomo I).

Por ello, Vertov prescinde de todo lo que pueda modificar la realidad: guión, actores, maquillaje, decorados e iluminación (Gubern, 1997, pp. 148-149). Este movimiento llamaba también la atención sobre sorprender al hombre en su vida. Quería filmar "la vida de improvisto" con el desconocimiento de las personas grabadas (Sadoul, 1998, pp. 165). Por otro lado, en esta época ya se vendían cámaras portátiles, la Sept y la Kinamo, que facilitaban el trabajo. En 1934 Vertov rodó Tres cantos a Lenin, que incorpora la entrevista filmada, adelantándose al Cinéma-Verité, que analizaremos más adelante.

\footnotetext{
${ }^{4}$ La masa se convierte en el protagonista de la película, como el proletariado de los Lumière y las vidas anónimas que protagonizarán los programas de telerrealidad
} 


\subsection{La intención interpretativa de Jean Vigo}

El director de cine francés Jean Vigo presentó el 28 de mayo de 1930 el cortometraje documental Sobre Niza (À propos de Nice) en París. Utilizó personajes pertenecientes a la actualidad y no mostró testimonios objetivos sino un punto de vista personal documentado, creando así el primer documental social francés. Vigo partió del montaje intencional de Vertov y aportó la intención interpretativa al cine de información (García Jiménez, 1999, p. 2, Tomo I).

Sobre Niza es una especie de ensayo fílmico en tono satírico que explora las desigualdades sociales de la Niza de los años 20, lanzando un feroz ataque contra los veraneantes burgueses. Poco a poco, desaparece la imagen cinematográfica como simple escaparate de la realidad para analizar y dar un significado a lo que se cuenta, y aportar así algo al mundo, fin imprescindible en todo trabajo documental y periodístico (Barnouw, 1998, p. 71-72).

\subsection{La construcción de la realidad y la aprendida espontaneidad de Robert Flaherty}

El cine nació como documental y, posteriormente, se convirtió en testimonio gráfico de actos históricos, en "actualidades reconstruidas", protagonizados por los notables de la época. De todos modos, estos documentales limitaban al cine a pasivo reproductor de las apariencias de las cosas hasta la llegada de Robert Flaherty con su material visual construido y articulado con intención, centrado en el hombre (Sánchez Noriega, 2006, p. 120-122).

El director norteamericano profundizó a lo largo de tres décadas (años 20, 30 y 40) en la observación del ser humano. Así, Flaherty recorrió el mundo en busca de momentos de belleza, sentando las bases de la estética del documental. Sus personajes salen de la actualidad, al igual que con Vigo, pero son sometidos a un entrenamiento y aprendizaje. Se convierten así, en actores de su propia vida, intentando olvidarse de la cámara e interpretando con aprendida espontaneidad (García Jiménez, 1999, pp. 2-3, Tomo I). Siguiendo este procedimiento dirigió en 1922 Nanuk, el esquimal (Nanook of the North), que narra las duras condiciones de vida de una familia esquimal del ártico. Los temas utilizados por Flaherty son los más simples y a la vez los más complicados de tratar: las vicisitudes del ser humano (Gubern, 1997, p. 242-243).

En cuanto a la realización, utilizó en Nanuk recursos expresivos que en aquella época sólo utilizaba el cine de ficción. Empleó los primeros planos para penetrar en los protagonistas, panorámicas para mostrar el entorno y picados para aumentar la presencia de la nieve. También predominaban las tomas largas y el montaje de continuidad para transmitir impresión de que las acciones se sucedían por sí solas frente a los ojos del realizador (Paz \& Montero, 2002). 
Nanuk tuvo mucho éxito y una de las razones puede ser su temática: la lucha del hombre por la supervivencia, al igual que las vidas anónimas que protagonizan la telerrealidad y que también luchan en su día a día. Erik Barnouw recoge en su obra, El documental. Historia y estilo, palabras del propio Flaherty: "El vivo deseo que tenía de hacer Nanuk se debía a mi estima por esa gente, a la admiración por ella; yo deseaba contarles a los demás algo sobre ese pueblo" ( Barnouw, 1998).

La técnica de Flaherty fue aplicada en los docudramas de los años 70, cuyos protagonistas eran las personas que habían vivido los hechos originarios que se narraban. Según Ma Antonia Paz y Julio Montero,

la prehistoria del documental se prolonga hasta los comienzos de la década de los 20 cuando aparece la primera formulación concreta del género con Flaherty" y "el documental sobrevive en el reinado de la televisión asimilando algunas de sus técnicas y abriéndose nuevas fórmulas, que logran tener presencia destacada hasta nuestros días" (Paz \& Montero, 2002, p. 26).

Por otro lado, supone la esencia de los programas de telerrealidad de hoy, en los que se dirige la realidad para mostrar la vida cotidiana del ser humano.

\subsection{El documental y la Escuela Británica}

El documental se entiende como un reflejo y una construcción de la realidad. Comenzó a finales del cine mudo y tuvo un gran impulso en Europa de la mano de las vanguardias, que se fijaron en la modernidad y la innovación. El padre del término documental, John Grierson, dotó a este género de valores semánticos e introdujo el cine encuesta, durante los años 30 y 40. Quería llegar más lejos que Flaherty capturando la realidad de un modo más directo. En 1929 realizó el documental Pescadores a la deriva (Drifters), sobre las tareas de la pesca del arenque en el mar del Norte, iniciando así el Realismo, influido por el cine de Vertov. Las películas de la teoría realista tenían como premisa mostrar la vida tal cual es, al igual que la telerrealidad, y desde el principio, está ligada a un sentido de la función social del arte.

La Escuela Británica supuso una doble aportación. Por un lado, añadió al género documental el componente persuasivo, es decir, la información audiovisual se convirtió en instrumento de diálogo democrático. Y por otro lado, aportó el ya citado cine encuesta, que supuso una innovación metodológica, un intenso trabajo de documentación y el análisis y la organización del material recogido. Este documento será utilizado posteriormente como elemento esencial en los reportajes de televisión y se llamará entrevista o totales (García Jiménez, 1999, p. 3-4, Tomo I).

Junto a la Escuela Británica se desarrolló el documental de propaganda del período de entreguerras y la guerra. Fueron principalmente trabajos ideológicos y sirvieron de gran ayuda a los nazis. 
Entre 1934 y 1935, la cineasta oficial del régimen nazi, Leni Riefenstalh, realizó el documental sobre el nazismo Triunfo de voluntad (Triumph des Willens), que relata la manifestación a favor de Hitler de 1934. La puesta en escena se organizó para conseguir un efecto espectacular y la realidad se construyó para favorecer al nazismo (Sánchez Noriega, 2006, p. 122-124). ${ }^{5}$

Por otro lado, el gobierno canadiense creó en 1939 La National Film Board6 (NFB) y la encomendó a Grierson, quien se propuso "explicar Canadá a los canadienses y a los extranjeros" (Cit. en García Jiménez, 1999, p. 6, Tomo I). Tras la II Guerra Mundial, Grierson regresó a Gran Bretaña y el documental canadiense se consolidó gracias a tres factores: al impulso del Gobierno a la información audiovisual; a la creación de una distribuidora de cine de $16 \mathrm{~mm}$. en versión doble para superar los problemas lingüísticos; y a la llegada de la televisión.

La NFB desarrolló una técnica documental a mediados de la década de los 50, que consistía en mezclarse con la cámara entre las gentes de las pequeñas ciudades, con el objetivo de vivir su propia cotidianidad. La televisión consolida este movimiento, el Ojo-Inocente, que se impone a partir de la realización de Paul Tomkowitz: guardagujas de la vía del tren (Paul Tomkowitz: Street-Railway Switchman, 1953), de Roman Kroitor y de Corral (1954) de Colin Low (García Jiménez, 1999, pp. 6-7, Tomo I).

\subsection{El reportaje cinematográfico de la II Guerra Mundial}

En la II Guerra Mundial destaca el cine reportaje bélico estadounidense de Frank Capra y las crónicas de John Huston y William Wylder. De Capra tiene especial interés el cine reportaje Por qué luchamos (Why we fight, 1941-1945), formado por cortometrajes de 20 a 30 minutos, en los que se mezclaban crónicas periodísticas, montajes de viejos reportajes cinematográficos, secuencias construidas en estudios y noticiarios de actualidad, entre otros elementos. Los reportajes de investigación y denuncia tratan de advertir sobre problemas a los ciudadanos, y su objetivo es conseguir reacciones y actuaciones en los espectadores que propicien cambios para mejorar la situación (Paz \& Montero, 2002, p. 301-314).

Después de la II Guerra Mundial, Roman Karmen, documentalista y operador de noticiarios de la URSS, desarrolló un periodismo visual muy personal e introdujo en los reportajes una gran dureza. En la posguerra, los reportajes cinematográficos de actualidad constituyen el único documento informativo visual para la mayoría de los ciudadanos. La información audiovisual experimenta un gran impulso cuando las cadenas de televisión estadounidenses, NBC y CBS, comienzan a retransmitir noticiarios televisados (García Jiménez, 1999, p. 153-154, Tomo II).

\footnotetext{
5 Sobre Leni Riefenstalh y El triunfo de la voluntad véase también Paz y Montero, 2002, pp. 200-207.

${ }^{6}$ La National Film Board es una organización pública canadiense que tiene como objetivo producir y distribuir películas para promover el país por el mundo. La NFB es reconocida por sus documentales y por sus cortos animados.
} 
En Hollywood, la revolución de Orson Welles y su Ciudadano Kane (1941) fue una nota excepcional en el mediocre panorama artístico de los años de la guerra. El precoz director realizó una obra maestra repleta de significaciones, tanto de orden psicológico, como social y moral (Bazin, 2002, p. 72).

El cine ha descubierto su importancia como espejo de la Historia y como informador. Su objetivo es contribuir a que los hombres puedan conocerse y comprenderse mejor y, en consecuencia, se sientan solidarios en sus problemas y en sus objetivos.

\subsection{El cine como testimonio verídico y el Cinéma-Verité}

En la década de los 40, el cine francés aportó testimonios verídicos sobre la Resistencia francesa al nazismo durante la II Guerra Mundial. Otro momento significativo del cine galo fue un movimiento de inspiración flahertiana. Farrebique (1947), de Georges Rouquier, relata una historia cuyo objetivo era analizar los habitantes de una región, que pudiera estar en cualquier parte del mundo para mostrar su cotidianidad. Trabajó con una familia que conocía desde la infancia y a la que entrenó para que sus miembros se convirtieran en actores de sus propias vivencias, al igual que Flaherty y su Nanuk, el esquimal (Gubern, 1997, p. 447-449).

Ya en los años 50, surgió en Francia un grupo de cineastas que defendieron la objetividad del cine como registro de la verdad. El filósofo, sociólogo y político Edgar Morin bautizó a este movimiento como Cinéma-Verité. Cabe destacar también al etnógrafo Jean Rouch, quien hizo avanzar este género en colaboración con Morin, al rodar Crónica de un verano (Chronique d'un été, 1961).

Esta experiencia pretendía registrar la personalidad y los conflictos íntimos de los individuos estudiados en la película, a partir de la pregunta inicial ¿es usted feliz? Estimulado por la demanda de las cadenas de televisión, se desarrolló el posteriormente denominado Cine-Directo, cuya cámara penetraba con ojo fisgón en todos los ambientes e intimidades (Barnouw, 1998, p. 221-223).

El Cinéma-Verité se apoya en la encuesta como el modo más idóneo para penetrar en la intimidad humana. Sus autores defienden que las personas, puestas ante la cámara y en virtud de la aplicación de ciertas técnicas, llegan a desvelar lo más hondo de su personalidad (Barnouw, 1998, p. 223-224).

La cámara, cada día más ligera, permite dar validez y sentido al documento sin necesidad de la mediación estilística del autor. El operador camufla la cámara y la excluye de todo propósito de ficción, facilitando el movimiento del equipo de grabación y convirtiéndolo en otro personaje dramático de la historia, que atrape a los espectadores de principio a fin. 
Por su parte, a mediados de la década de los 50 surge en Inglaterra el movimiento Free Cinema, que pretende restablecer el contacto con la vida diaria, dejándole al ser humano la palabra. Gracias a los equipos más ligeros, penetraban en lugares que la sociedad se empeñaba en ignorar o mantener ocultos.

Los ejemplos más significativos son los del primer período: Todos los días excepto Navidad (Every Day Except Christmas, 1955), de Lindsay Anderson, sobre los trabajadores del mercado de Covent Garden en Londres, o Somos los chicos de Lambeth (We are the Lambeth's Boys, 1956), del realizador Karel Reisz, sobre el modo en que empleaban el tiempo libre los jóvenes del barrio londinense ${ }^{7}$ (Barnouw, 1998, p. 204-206).

Las nuevas técnicas han sido fundamentales en la evolución del cine hacia formas más democráticas de comunicación social. El documental y el cine reportaje, desplazado de las pantallas de cine a las de televisión, propiciaron esta evolución técnica. Lejos está ya la imagen cinematográfica como simple escaparate de la realidad y hoy el documental supone un cine reflexivo y testimonial, al igual que el reportaje en televisión (Paz \& Montero, 2002, p. 301-314).

En los anteriores epígrafes hemos hecho un repaso por los diferentes movimientos cinematográficos que creyeron en la realidad como mejor apuesta para mostrar la cotidianidad del ser humano. A continuación, vamos a analizar los orígenes del reportaje de televisión, que es el germen de la telerrealidad.

\subsection{La llegada de la televisión y los orígenes del reportaje}

En la televisión, recordemos que la NFB canadiense se había propuesto explicar Canadá a los canadienses y a los extranjeros. A pesar de la II Guerra Mundial, la serie El Mundo en Acción (The World in Action, 1941-1946) permitió a Stuart Legg conseguir la medida justa del reportaje de televisión, mezclando los experimentos de Vertov y de Louis Rochemont, quien combinaba noticias con entrevistas y dramatizaciones (García Jiménez, 1999, p. 153, Tomo II).

El reportaje experimentó un gran impulso con la llegada de la televisión y con la aparición de las living camera, mucho más ligeras. De este modo, la producción del reportaje la llevan a cabo equipos reducidos, normalmente, un director, un operador de cámara y un técnico de sonido. La mayoría de los programas de telerrealidad de hoy lo graban exclusivamente un reportero y un operador de cámara.

En Inglaterra, la $B B C$ se convierte en la década de los 60 en el gran modelo de la televisión estatal y desde su origen tuvo como gran propósito informar, educar y entretener.

\footnotetext{
${ }^{7}$ Lectura de varias páginas Web, entre ellas www.miradas.net/2006/n50/clasico.html y www.documentarufilms.net.
} 
Desde su modelo experimental en los años 1946 y 1947 dio una gran importancia a los informativos y a los documentales (Faus Belau, 1995, p. 197-200). Por su parte, la televisión comercial de Estados Unidos se inauguró en 1946 y el espectáculo audiovisual en casa comenzó a sustituir al cine (Gubern, 1997, p. 297-298). ${ }^{8}$

En la década de los sesenta se cultivó un cine político, los llamados Newsreels, en los que la cámara se convierte en arma de lucha contra el orden establecido. William Klein, fotógrafo prestigioso y director de cortometrajes a favor de los derechos civiles, trabaja en la televisión francesa desde 1962. Utilizando las técnicas del Cinéma-Verité convirtió al campeón de boxeo, Cassius Clay, en elemento conductor de su trilogía sobre la alineación norteamericana (García Jiménez, 1999, p. 6, Tomo I).

Al igual que el cine, la televisión ha estado desde su nacimiento al servicio de los acontecimientos históricos y sociales, y ha desempeñado en numerosas ocasiones un papel fundamental. En Estados Unidos, según los estudios de sociología política del país, la televisión tuvo un papel evidente en las campañas electorales: favoreció la elección de Eisenhower contra Stevenson en 1956 y cumplió una función decisiva en la de Kennedy contra Nixon en 1960 (Albert y Tudesq, 1982, p. 88). Además, la guerra de Vietnam (1964-1975) fue la primera que se emitió en directo, revolucionando los informativos.

La televisión decidió estar permanentemente en Vietnam, no sólo para cubrir la guerra sino también para hablar con los soldados norteamericanos. Otro hito televisivo fue la llegada del hombre a la luna en 1969, acontecimiento que fue retransmitido a muchas partes del mundo, pero lo más importante es que se hizo como un espectáculo (Faus Belau, 1995, p. 197-200).

Por otro lado, gracias a las nuevas condiciones tecnológicas, productores como Robert Drew llevaron a cabo reportajes, dentro de la fase del Cinéma-Verité, destinados a la televisión. Con la pequeña pantalla en los hogares desaparece como género el cine reportaje. La televisión desplazó también a la radio con sus documentales: los programas en profundidad (in depth) y los directos. Recordemos que los sociólogos y la televisión cultivaron de un modo extenso y natural la encuesta. La telerrealidad se basa, en gran parte, en la psicología de los reporteros para obtener información de los personajes a los que entrevista, y en la capacidad de provocar del operador de cámara, por ejemplo con la distancia y sutiles movimientos.

En España, cabe destacar en la década de los 60 los programas de TVE A vuelta de correo, de Jesús Álvarez, y Encuesta, en el que Carlos Sentís salía a la calle para recoger opiniones de los telespectadores sobre asuntos de actualidad. Esto es el comienzo de lo que hoy conocemos como reportero, que trabaja en la calle en busca

\footnotetext{
${ }^{8}$ Sobre las fechas del nacimiento de la televisión en los distintos países, véase también Bustamante, 2000, p. 29.
} 
de totales (Díaz, 2006, p. 54-56).

Las primeras experiencias televisivas las realizaron dos compañías en 1948: la Philiphs, holandesa pero con afiliación en España, y la RCA norteamericana. Pero la fecha oficial de la llegada de la televisión a España fue el domingo 28 de octubre de 1956, con la inauguración de las primeras emisiones regulares del NO-DO9 ${ }^{9}$ desde los primeros estudios de TVE en Paseo de la Habana de Madrid (Monterde, 2000, p. 194-195).

El primer informativo no tendrá lugar hasta el 2 de noviembre de 1957, gracias a acuerdos con agencias estadounidenses $(C B S, U P I)^{10}$. Al igual que en el cine documental, la programación y la información en esos años coinciden con los grandes acontecimientos históricos y sociales, en este caso del régimen Franquista (Bustamante, 2000, pp. 29-33). Y los programas de reportajes en TVE comenzaron en 1958 con el telediario de los domingos, llamado Telecrónica.

El 16 de octubre de 1964 se estrenó A toda plana, inspirado en el programa francés Cinco columnas en el frente (Cinq colonnes à la une), dirigido por Pierre Lazareff, periodista de París Match. El programa, que finalizó el 5 de mayo de 1971, consistía en cuatro o cinco reportajes de diez a quince minutos sobre temas variados (Díaz, 2006, pp. 150-151).

Fraga Iribarne, ministro de Información y Turismo en el Gobierno de Franco desde 1962, impulsó la televisión con un ánimo principalmente culturizador. Se crearon programas didácticos como Escuela de Matrimonios (1967) y Conozca usted España (1965-1966), un formato documental para mostrar el país a quienes no viajaban y fomentar el Turismo.

Se trata del primer programa de reportajes de viajes, tan en auge en la actualidad. Y en 1965 se creó La 2, que contribuyó a esta línea educacional (Díaz, 2006, p. 183-186). A toda plana fue el origen de otros programas de grandes reportajes como Los Reporteros, que duró poco y en 1972 se convirtió en Datos para un informe, un informativo semanal de treinta minutos. Buscaba la noticia con crudeza más que el documental elaborado. En la temporada 2011-2012, el heredero de todos estos programas es En portada, que se emite en el Canal 24 horas de TVE cada quince días los domingos a las 22:30 h., con el mismo leit motiv: contar lo que pasa más allá de nuestras fronteras.

\footnotetext{
${ }^{9}$ El NO-DO (Noticiarios y Documentales), creado por el Gobierno Franquista, era el noticiario que se proyectaba obligatoriamente en los cines españoles antes de cada película, entre 1942 y 1981 .

10 Sobre los primeros informativos televisados en España y su relación con las agencias norteamericanas, véase Bustamante, 1988, p. 122.
} 
Por otro lado, TVE creó La historia de la semana, un programa formado por entrevistas y reportajes con personalidades públicas y personajes curiosos. Otro programa de este tipo fue Cada semana una historia. Estos reportajes fueron el embrión de Ésta es su vida, basado en el programa norteamericano This is your life. La versión española comenzó a emitirse el 3 de octubre de 1962, presentado por Federico Gallo y dirigido por Eugenio Pena. El espacio se centraba en realizar un recorrido por la vida de un personaje anónimo, presente en el plató. Ninguno de estos programas existe en la parrilla de la televisión pública en la temporada 2011-2012 (García Jiménez, 1999, p. 155-156, Tomo II).

El 31 de marzo de 1973 iniciaba su carrera Semanal Informativo11, que en la siguiente temporada se llamó Informe Semanal. Un programa de reportajes, de entre diez y treinta minutos, que aún sigue en antena y que se emite en TVE los sábados a las 21:30 h., dirigido por Alicia Gómez Montano desde 2004 y presentado por Ana Roldán desde 2010. Pedro Erquicia fue el encargado de poner en marcha el programa, que dirigió de 1973 a 1978, y ha sido un gran impulsor del gran reportaje. Se basó en la fórmula del formato estrella de la BBC: 60 minutos (60 minutes).

En 1974 se produce la consolidación del programa, en el que emergen los problemas sociales. Por aquel entonces, el director era Juan Luis Cebrián y se estrena el rostro más conocido y carismático del programa, Rosa María Mateo, a la que seguirá Pedro Erquicia (Magro, 2003, pp. 14-23). Este último dirigió y presentó Documentos TV, de 1990 a 2008. El programa arrancó el 29 de abril de 1986 para La 2 de TVE y en la temporada 2011-2012 continúa emitiéndose los sábados a las 22:30 h., dirigido por Manuel Sánchez Pereira. Nació con la vocación de ofrecer otra visión de la realidad con un tratamiento serio y riguroso ${ }^{12}$.

Y como claro germen de los programas de telerrealidad de hoy, como Callejeros y Vidas Anónimas, cabe destacar el programa Vivir cada día (TVE), dirigido por José Luis Rodríguez Puértolas, y que se emitió entre 1978 y 1988. Con la misma duración que el programa de La Sexta, 50 minutos, el docudrama pretendía ser un reflejo de la vida cotidiana de personas anónimas, que normalmente no eran objeto de atención de los medios de comunicación. Vivir cada día ganó dos Premio Ondas (1979 y 1983) y dos TP de Oro (1980 y 1983), al Mejor Programa Informativo y de Actualidad. En su día tuvo un gran éxito y se mantuvo durante una década, logro que todavía no ha conseguido ningún programa similar en una televisión comercial.

\footnotetext{
11 Informe semanal tiene sus orígenes principalmente en Telecrónica y en A toda plana, citados anteriormente. Sobre su historia véase también la Web del programa: www.informesemanal.tve.es. 12 Sobre Documentos TV véase la Web del programa: www.rtve.es/noticias/documentos-tv/.
} 
Con la Ley de la Televisión Privada en 198813, comienzan a surgir las cadenas comerciales, que abrirán un amplio abanico de posibilidades, apostando también por la información y creando nuevos formatos como los programas de reportajes de telerrealidad, cuyo auge tendrá lugar sobre todo a partir de la temporada 2007-2008, cuando cada cadena quiere crear su propio Callejeros y Vidas Anónimas. Comienza así la interminable batalla por la audiencia, cada vez más dura y competitiva.

A continuación, vamos a explicar brevemente el proceso de elaboración de Callejeros y Vidas Anónimas, en cuanto al estilo de grabación, para entender cómo se muestra y se dirige la realidad en este tipo de formatos para crear un reportaje de éxito, que atrape a la audiencia de principio a fin.

\section{Callejeros (Cuatro)}

La periodista Carolina Cubillo y gran parte del equipo que realizaba el programa de reportajes Mi cámara y yo, para Telemadrid, dejaron el canal autonómico madrileño para comenzar a nivel nacional Callejeros, en Cuatro. Su primera emisión fue Simplemente María, sobre el nacimiento de una niña, en noviembre de 2005 y iqué mejor que un nacimiento para el estreno! Como dice el subdirector de Callejeros, Nacho Medina, el programa muestra "la realidad a borbotones". ${ }^{14} \mathrm{Y}$ lo más importante de éste y los demás formatos similares son sus personajes protagonistas, las vidas anónimas, los héroes y villanos de la calle, que protagonizan, en este caso, un reportaje de 35 minutos. Pero, lo que ha hecho que Callejeros haya creado escuela en los programas de reportajes es su característico estilo de grabación, imitado por la mayoría de los formatos similares estrenados a raíz del programa de Cuatro.

El reportero de Callejeros es el director del reportaje y se encarga de todo su proceso de elaboración. Antes de grabar, elabora una estructura previa para el reportaje, aunque no escribe un guión. Pero sin duda, lo más importante del programa de Cuatro es la cercanía, el trato humano de los reporteros con los personajes de la calle. Para Carolina Cubillo, "el éxito del programa son los reporteros", ya que considera que "son las personas con mayor sensibilidad para hacer periodismo de calle". ${ }^{15}$

En cuanto a las técnicas de realización, Callejeros utiliza el Plano Secuencia, que consiste en un único plano sin cortes, que imita a la vida diaria y al directo. "Es casi un dejar hablar a los personajes y a las imágenes" (Millerson, 1983, p. 183). La cámara se convierte en un personaje provocador, que muestra la realidad y hurga en la

\footnotetext{
${ }^{13}$ En la Web del BOE, www.boe.es, puede consultarse la Ley 10/1988, de 3 de mayo, de Televisión Privada. Publicada en BOE número 275 de 16/11/1988, páginas 32599 a 32601.

${ }^{14}$ Declaración extraída de la rueda de prensa que realizó Cuatro para presentar el reportaje especial de Callejeros, titulado Palma Palmilla, del reportero Jalis de la Serna, que se emitió el 26 de octubre de 2007. El encuentro con los medios tuvo lugar el 24 de octubre.

${ }^{15}$ Declaraciones extraídas de la entrevista realizada por Brenda Vázquez La Hoz a Carolina Cubillo el 30 de abril de 2008. Ver entrevista íntegra en la Tesis Doctoral La realidad dirigida en los programas de telerrealidad: Análisis de Calleieros u Vidas Anónimas, 2011, pp. 7-13 de los Anexos
} 
personalidad humana, al igual que en el Cinéma-Verité.

Se utiliza también la Cámara Subjetiva, donde el objetivo se convierte en los ojos de la audiencia, que tiene el punto de vista de todos los protagonistas, consiguiendo una gran identificación e implicación en la historia. Se establece así una relación muy especial entre la audiencia, los personajes y el equipo de grabación, convirtiéndose ésta en una de las principales claves del éxito de la telerrealidad.

Y como en este tipo de formatos tan sólo graban dos personas, el operador de cámara es el realizador de campo, que elige cómo mostrar a la audiencia cada secuencia de la forma más atractiva y cercana posible.

\section{Vidas Anónimas (La Sexta)}

La Dirección de Callejeros creó, en octubre de 2007, Vidas Anónimas para La Sexta, un formato más íntimo y elaborado, que fue evolucionando hasta convertirse en un programa de 50 minutos, protagonizado por 3 ó 4 personajes muy diferentes. Según el subdirector del programa en su primera temporada, Nacho Medina, la idea del programa

surgió a raíz de conocer personajes de la calle que eran muy poderosos, por ejemplo, un hombre de 80 años de edad, que vestía como un punki, recogía basura de la calle y que había sido boxeador. Pensamos en seguir 24 horas a esas personas para hacer un programa de reportajes. ${ }^{16}$

El estilo de grabación de Vidas Anónimas es muy similar al de Callejeros, en cuanto a las técnicas de realización, aunque al haber una mayor dramatización de los hechos, este formato se caracteriza porque el reportero y el operador de cámara van construyendo cada una de las secuencias con sus personajes. De esta forma, los reporteros se convierten en directores de la realidad de gente corriente, que a su vez son actores de su propia cotidianidad. Ésta es la esencia del programa: mezclar la realidad dirigida y la realidad espontánea, simulando un continuo monólogo del personaje.

Por su parte, los ciudadanos anónimos actúan tanto en las acciones que harían aunque la cámara no existiera, como ir a trabajar, y también en aquellas propuestas por el reportero, que buscan obtener reacciones atractivas y el contraste. Esto nos recuerda a Flaherty y la aprendida espontaneidad en su Nanuk, el esquimal (1922), documental que podemos considerar como el origen de la realidad dirigida en los formatos de telerrealidad de hoy.

\footnotetext{
${ }^{16}$ Declaraciones obtenidas de la entrevista realizada por Brenda Vázquez La Hoz a Nacho Medina, el 28 de mayo de 2008. Ver entrevista íntegra en la Tesis Doctoral La realidad dirigida en los programas de telerrealidad: Análisis de Callejeros y Vidas Anónimas, 2011, pp. 46-49 de los Anexos.
} 


\section{CONCLUSIONES}

Concluimos con este análisis sobre la tradición histórica de la telerrealidad y el estilo de grabación de dos de sus formatos, que hemos descubierto el origen de este género y algunas de las claves de su éxito.

En primer lugar, podemos afirmar que la telerrealidad responde a la voluntad de informar y de mostrar al hombre el hombre, que caracterizó a los inicios del cine y de la televisión. Por lo que, Callejeros y Vidas Anónimas no son ideas nuevas sino que representan esta esencia al enseñar realidades e historias de personas corrientes, que a su vez son extraordinarias.

Corrientes cinematográficas del siglo XX, como el Cine-Ojo de Dziga Vertov, que apostaron por la realidad para contar una historia, que rechazaban el guión previo y querían agitar la mente del espectador, son el origen de la televisión callejera. Fue Robert Flaherty quien sentó las bases estéticas del documental cinematográfico y televisivo. Su obra Nanuk, el esquimal (1922) representa el origen de la realidad dirigida en los formatos de telerrealidad, que llenan las parrillas de la televisión de hoy, y Vidas Anónimas es su mayor representante. En la década de los 50, se crea en Canadá el movimiento Ojo-Inocente, y en Francia el Cinéma-Verité con el objetivo de vivir la cotidianidad y de considerar el cine como registro de la verdad. Se crea así un cine reflexivo y testimonial, al igual que la telerrealidad.

La cámara de estos programas se convierte en un personaje dramático, como en el Cinéma-Verité, con el objetivo de conocer personas y hurgar en sus sentimientos. La cámara de Callejeros y Vidas Anónimas consigue extraer los sentimientos más profundos de algunas personas, que consideran la presencia del programa una oportunidad para alzar la voz y contar su historia a los demás. Los programas objeto de esta investigación comparten con los inicios del cine la pasión por la vida humana, pero añaden la dramatización y el guión.

Los reportajes de televisión nacieron también para mostrar a la audiencia su propia realidad. Informe Semanal ha sido uno de los formatos referencia de la telerrealidad. Continúa en emisión en la temporada 2011-2012 con su misma esencia: ir más allá de la información con seriedad y rigor. Además de TVE, el principal referente de la telerrealidad ha sido Telemadrid con la creación de Mi cámara y yo en 2001, y Madrileños por el mundo en 2005, que nos recuerdan al Cine Dogma, de directores como Lars Von Trier. Para ello, utilizan técnicas como simular que el reportero graba, dando sensación de videoaficionado y transmitiendo todavía más cercanía. 
Y en segundo lugar, concluimos que una de las principales claves del éxito de Callejeros es su estilo de grabación, que imita a la vida misma, y el trato cercano de sus reporteros. En cuanto a Vidas Anónimas, podemos afirmar que es el formato de este género que realiza una mayor dramatización de los hechos, a través de la dirección de la realidad, a cargo del equipo de grabación, y de la actuación de sus personajes protagonistas, para conseguir el reportaje más atractivo posible para la audiencia.

El programa de Cuatro continúa cinco años después en emisión, superando cada viernes la media de cuota de pantalla de la cadena, aunque con peores datos, debido a la pérdida de interés de sus exitosos temas sórdidos en favor de nuevas fórmulas temáticas y con historias más agradables y esperanzadoras. Por su parte, Vidas Anónimas dejó de emitirse en La Sexta, pero en la temporada 2010-2011 volvió para emitirse a diario junto a otros formatos de telerrealidad temáticos en La Sexta 2, obteniendo de nuevo una audiencia más que aceptable.

\section{REFERENCIAS}

Albert, P. \& Tudesq, A. J (1982). Historia de la radio y la televisión. México: Fondo de Cultura Económica.

Arnow, E. (1998). El documental. Historia y estilo . Barcelona: Gedisa.

Bazin, A. (2002). Orson Welles. Barcelona: Paidós.

Bustamante, E. (2000). Radio y Televisión en España. Historia de una asignatura pendiente de la democracia. Barcelona: Gedisa.

Cebrián Herreros, M. (2004). La información en televisión. Barcelona: Gedisa.

Díaz, L. (2006). 50 años de TVE. Madrid: Alianza Editorial.

Faus Belau, Á. (1995). La era audiovisual. Historia de los primeros cien años de la radio y la televisión. Barcelona: Ediciones Internacionales Universitarias.

García Jiménez, J. (1999). Información Audiovisual. Orígenes-Conceptos-Identidad (Tomo I). Madrid: Paraninfo.

García Jiménez, J. (1999). Información Audiovisual. Los géneros (Tomo II). Madrid: Paraninfo.

Gubern, R. (1997). Historia del cine (4 ${ }^{\mathrm{a}}$ ed.). Barcelona: Lumen.

Hueso Montón, Á. L. (1998). El cine y el siglo XX. Barcelona: Ariel Historia. 
Ituarte, L. \& Letamendi, J. (2002). Los inicios del cine. Desde los espectáculos precinematográficos hasta 1917. Barcelona: Ediciones del Serbal.

Magro, B. (2003). Informe Semanal. 30 años de historia. Barcelona: Plaza \& Janés.

Monterde, J. E. (2000). Historia del cine español. Madrid: Cátedra.

Paz, Ma . \& Montero, J. (2002). El cine informativo 1895-1945. Creando realidad. Barcelona: Ariel Cine.

Sadoul, G. (1998). Historia del cine mundial desde los orígenes (16 a edición). México D.F: Siglo XXI.

Sánchez Noriega, J. L. (2006). Historia del cine. Teoría y géneros cinematográficos, fotografía y televisión (4 $4^{\mathrm{a}}$ ed.). Madrid: Alianza Editorial.

Sorlin, P. (1996). Cines europeos, sociedades europeas (1939-1990). Barcelona: Paidós.

Vázquez La Hoz, B. (2011). La realidad dirigida en los programas de telerrealidad: Análisis de Callejeros y de Vidas Anónimas. Tesis Doctoral de la Universidad de Vigo, Facultad de Ciencias Sociales y de la Comunicación.

\section{Brenda Vázquez La Hoz}

Reportera de televisión y en la actualidad desempeña su trabajo en la Productora Faro, realizando un programa de reportajes para la Televisión de Galicia (TVG). Es Doctora en Comunicación por la Universidad de Vigo (3 de junio de 2011), Es Licenciada en Comunicación Audiovisual, con Diploma en Guión y Dirección de Cine y Televisión, por la Universidad Antonio de Nebrija, en Madrid (2004). Comenzó su carrera profesional como locutora de informativos en RNE-Vigo para continuar en televisión. En cuanto a su experiencia docente, ha impartido una sesión sobre La publicidad radiofónica en España (29 de septiembre de 2011), dentro del Curso de Especialista en Publicidade, Mercadeo e Consumo, Título Propio de la Universidad de Vigo, dirigido por el Profesor Luis Fernando Ramos.

\section{Mercedes Román Portas}

Profesora Titular de la Universidad de Vigo (Campus de Pontevedra), en la Facultad de Ciencias Sociales y de la Comunicación, Departamento de Psicología Evolutiva y de la Comunicación. Es Doctora en Ciencias de la Información (Periodismo) por la Universidad de Navarra (24 de octubre de 1994). Tiene el Grado de Doctora en Ciencias de la Educación (1982), también por la Universidad de Navarra, y es Licenciada en Filosofía y Letras por la Universidad de Valladolid (1982). Es autora de seis libros sobre varios periódicos gallegos, televisión y radio. El más reciente, Historia da radio en Pontevedra (2003), lo escribió junto a Aurora García González, Profesora Titular de la Universidad de Vigo. Ha publicado numerosos capítulos de libros. 